\title{
Effects of Semi-Ablative Fractional Radiofrequency Associated with Growth Factors in Stretch Marks: A Randomized Controlled Trial
}

\author{
Patricia F. Meyer1,2, Rodrigo Marcel V. Da Silva1,3, Liliane S. Vasconcelos', \\ Louhanne Christine B. Bezerra ${ }^{4}$, Maria Paula M. Oliveira4, Eneida M. Carreiro' ${ }^{2,5}$, \\ Ciro D. Soares ${ }^{6}$, Fabio S. Borges ${ }^{7}$, Monica Etrusco ${ }^{8}$, Joyce Rodrigues ${ }^{9}$, \\ Silene B. Ribeiro10, Hernan Andrés B. Ortiz ${ }^{11}$ \\ ${ }^{1}$ Federal University of Rio Grande do Norte (UFRN), Natal, Brazil \\ ${ }^{2}$ Physiotherapy Course at UNIRN, Natal, Brazil \\ ${ }^{3}$ Mauricio de Nassau Natal, Natal, Brazil \\ ${ }^{4}$ Physiotherapy Course at Potiguar University (UnP), Natal, Brazil \\ ${ }^{5}$ Potiguar University (UnP), Natal, Brazil \\ ${ }^{6}$ Graduate Program in Stomatopathology, State University of Campinas, São Paulo, Brazil \\ ${ }^{7}$ Postgraduate Program in Dermatofunctional Physiotherapy, Estácio de Sá University, Rio de Janeiro, Brazil \\ ${ }^{8}$ Minas Gerais Faculty of Medical Sciences, Minas Gerais, Brazil \\ ${ }^{9}$ São Judas Tadeu University, Butantã, Brazil \\ ${ }^{10}$ FSG Centro Universitário, Caxias do Sul, Brazil \\ ${ }^{11}$ Physiotherapy Course, Escuela de Kinesiología, Facultad de Ciencias de la Rehabilitación, Universidad Andrés Bello, \\ Santiago, Chile \\ Email: rodrigomarcelvalentim@gmail.com
}

How to cite this paper: Meyer, P.F., Da Silva, R.M.V., Vasconcelos, L.S., Bezerra, L.C.B., Oliveira, M.P.M., Carreiro, E.M., Soares, C.D., Borges, F.S., Etrusco, M., Rodrigues, J., Ribeiro, S.B. and Ortiz, H.A.B. (2021) Effects of Semi-Ablative Fractional Radiofrequency Associated with Growth Factors in Stretch Marks: A Randomized Controlled Trial. Open Journal of Applied Sciences, 11, 379-394

https://doi.org/10.4236/ojapps.2021.114028

Received: February 26, 2021

Accepted: April 10, 2021

Published: April 13, 2021

\begin{abstract}
Background: To investigate the effects of the association of semi-ablative fractional radiofrequency (RFF) with growth factors in stretch marks. Methods: This is a randomized controlled trial. The sample consisted of 28 female patients with complaints of gluteus or abdomen striae and divided into 2 equitable groups, named G1 (semi-ablative RFF without active principle association) and G2 (semi-ablative RFF with active principle association), being subdivided into G-1A and G-2A (abdominal applications) and G-1B and G-2B (gluteus applications). A photographic and histological analysis was performed using questionnaires about inflammation, presence of adverse effects and satisfaction of volunteers. Photographic analysis showed a reduction in the amount of striae alba in all groups. Results: The histological analysis showed
\end{abstract}


Copyright $\odot 2021$ by author(s) and Scientific Research Publishing Inc. This work is licensed under the Creative Commons Attribution International License (CC BY 4.0).

http://creativecommons.org/licenses/by/4.0/ an increase in fibroblast activity, collagen type I, and blood vessels, especially in the groups that associated the RFF with the active principle. In the inflammation analysis, the groups that performed intervention with active ingredients showed lower inflammatory signal. All groups had a reasonable level of satisfaction after the interventions; however, the group that used active ingredients reported greater results. Conclusion: The association of semi ablative RFF with growth factors showed a reduction in clinical inflammatory signs, mainly in the first 15 days, as well as higher collagen production, verified in 30 days, with satisfactory clinical results in all groups.

\section{Keywords}

Striae Distensae, Collagen, Wound Healing

\section{Introduction}

Stretch marks are defined as linear and atrophic plaques associated with the continuous and progressive stretching of the skin, as well as hormonal modulation, being bilaterally located [1]. For the treatment of this type of injury, several techniques have been applied to attenuate the albas striae [2]. In clinical practice, the semi-ablative fractional radiofrequency (RFF) has been used to promote tissue renewal by stimulating collagen through controlled thermal damage directly to the dermis. Thus, extremely effective and safer treatment results are produced compared to ablative radiofrequency, which may increase the risk of hyperpigmentation. It has considerably improved facial wrinkles, eyelid, perioral, scars and stretch marks, and skin sagging. A study carried out in animals demonstrated that the different radiofrequency responses in the collagen tissue, in which the evolution of the collagen production response was observed, as well as demonstrated [3].

The use of radiofrequency is already widely reported in the literature, with observations concerning the responsive production of collagen fibres, elastin, and the induction in the production of fibroblast growth factors [4] [5]. With temperatures in the applicable therapeutic range, changes in collagen extensibility are observed. Radiofrequency acts on at least 3 tissue levels: microcirculation, adipose tissue and interstitial matrix. In the microcirculation, radiofrequency stimulates the micro hyperemia, which consists of overcoming the artery-arteriole deficit and increasing the flow speed in the capillaries. At the adipocyte level, it increases the microcirculation, increasing the thermal and enzymatic gradient, activating lipolysis by releasing catecholamines and increasing the temperature, increasing the extensibility of the fibers, of the connective tissue with a consequent improvement of the micro-circulatory and cell interchange [3] [4] [5].

This response on connective tissue induces significant responses in clinical and aesthetic improvement in different pathologies and aesthetics in different pathologies, observing the release of fibroblast growth factors which become 
important in the process of neocolagenization. The use of fractional radiofrequency in stretch marks has also been mentioned, with [4] [5]. The use of fractional radiofrequency in striae has also been mentioned in regard to the appearance improvements, collagen production, and inflammatory cells, which are combinations that can modulate the connective tissue response [6].

In addition to the use of semi-ablative RFF for the treatment of connective tissue, it has been observed that the association with active principles favours collagen and elastin modulation. The drug delivery system refers to the transdermal delivery of selected assets and can optimize the desired results through drug transportation through the skin, with the advantage of being easily accessible, safe, and effective [4].

Several active ingredients can be used for drug delivery. Growth factors are highly indicated, including TGF- $\beta 3$ (Transforming Growth Factor). The TGF- $\beta 3$ is able to act on the growth, proliferation, and differentiation of several cell types, mainly fibroblasts. It is one of the potent fibrogenic mediators that can considerably increase the levels of the skin's collagen and elastin; and it is also highly inflammatory. There are other substances that can be used to treat stretch marks via drug delivery: Phaseolus lunatus, rutin, and matrikines. These are antioxidants that contribute to the stabilization of mast cells, leukocyte inhibitors, consequently disadvantaging elastase activity. Matrikins (which are messenger peptides from extracellular matrix degradation) promote an excellent activity in the reconstruction of damaged extracellular matrix. Other active principles that increase the firmness of connective tissues are components such as hydroxypropyl methylcellulose, pullulan, porphyridium cruentum extract, which also favour fibroblastic activity. The active principles described are used in different ways in clinical practice, and therapies combined with their use of substances have promoted interesting results [5].

However, in recent years, the development of studies on skin and aesthetic pathologies has promoted the knowledge concerning the functional clinical aspects resulting from stretch marks. Currently, several approaches are being used in stretch mark therapy, not seeking to cure the stretch mark, but to improve their visual appearance and tissue composition, among them, fractional radiofrequency and the use of active principles [6]. Therefore, the purpose of this study was to investigate the effects of semi-ablative RFF associated with the use of growth factors in the treatment of stretch marks.

\section{Methods}

This study is a randomized controlled trial. This study was submitted to the Research Ethics Committee (CEP) of Potiguar University (UnP) and approved with the opinion approval number: 3,134,050 and it was registered at https://www.clinicaltrials.gov obtaining identification trial number NCT03931525. The participants were instructed as to the procedures that would be performed and signed the consent form. 
The study included women, aged 18 - 35 years old, with the presence of striae alba in the gluteus and abdomen region, with no reports of collagen-related diseases, healing problems and/or protein synthesis, which were not under the effects of drugs that promote physiological changes in the skin and collagen, were not under dietary restriction (diets, dietary rehabilitation, among others) that could significantly influence the physiology of the skin. Volunteers who presented exacerbated inflammatory reaction, excessive pain after application, discomfort or refusal to participate in the study were excluded.

The study sample consisted of 28 female patients with striae alba in the gluteus or abdomen region. However, 12 volunteers were excluded due to withdrawal during treatment. The volunteers were subdivided as shown in Table 1. Based on the initial values obtained from a pilot study performed with 8 volunteers, a sample of 40 subjects was sufficient to detect a clinically important difference. A statistical power of $80 \%$ and an alpha of $5 \%$ were considered for the sample calculation. The calculation was performed via the site http://www.openepi.com. This study followed the consort's recommendations. Figure 1 shows the study design.

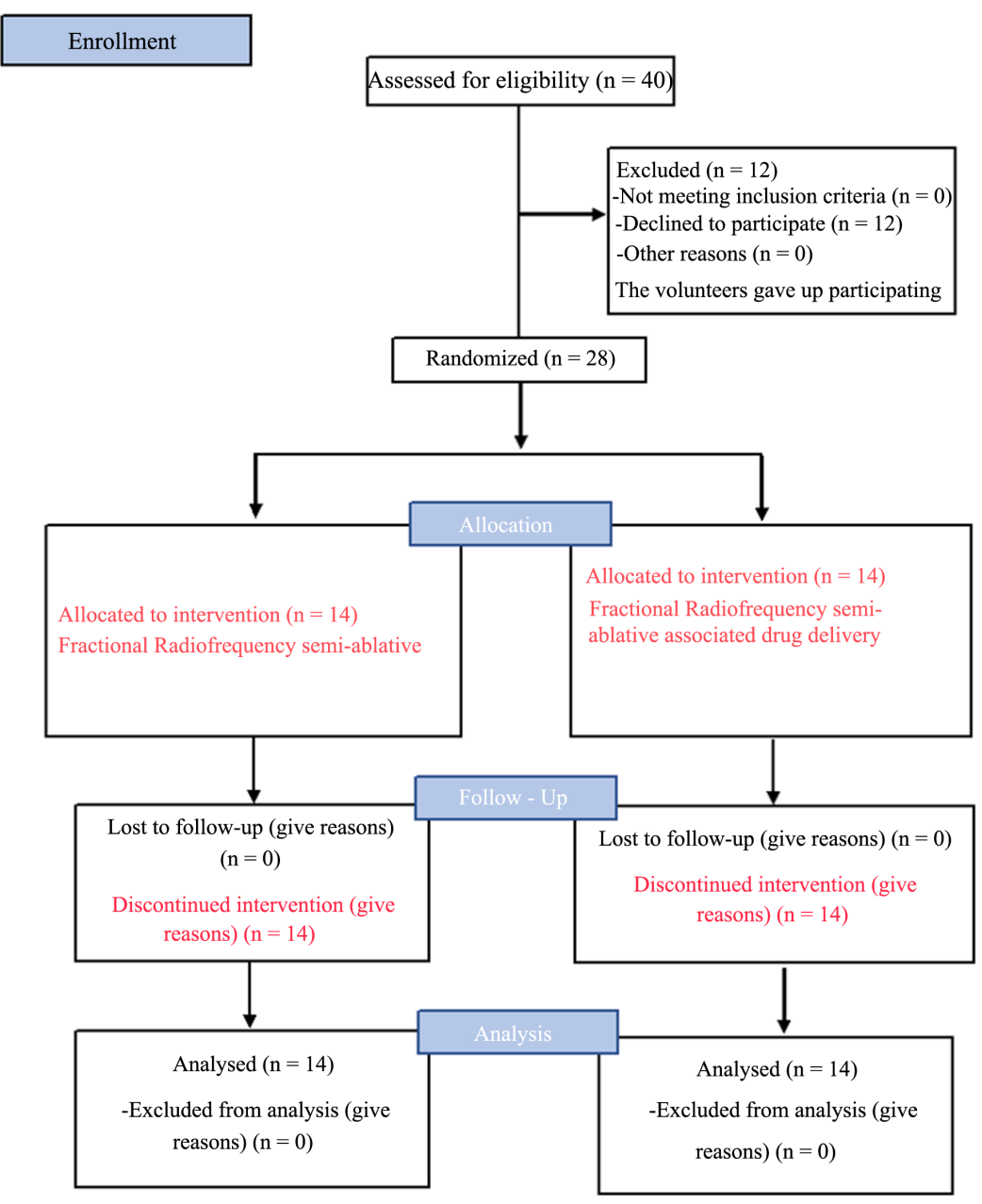

Figure 1. Study sample. 
Table 1. Study sample.

\begin{tabular}{|c|c|c|c|c|}
\hline Group & Subgroup & Sample & Procedures & Intervention \\
\hline \multirow{2}{*}{ G-1 } & G-1 A & 10 patients & $\begin{array}{c}\text { Abdomen Stretch } \\
\text { Marks/RFF } \\
\text { Application }\end{array}$ & $\begin{array}{c}15 \text { days of interval } \\
\text { between interventions }\end{array}$ \\
\hline & G-1 B & 5 patients & $\begin{array}{c}\text { Gluteal Streaks/Drug } \\
\text { Delivery-Associated } \\
\text { RFF Application }\end{array}$ & $\begin{array}{c}15 \text { days of interval } \\
\text { between interventions }\end{array}$ \\
\hline \multirow{2}{*}{ G-2 } & G-2 A & 7 patients & $\begin{array}{l}\text { Abdomen Stretch } \\
\text { Marks/RFF } \\
\text { Application }\end{array}$ & $\begin{array}{c}30 \text { days of interval } \\
\text { between interventions }\end{array}$ \\
\hline & G-2B & 6 patients & $\begin{array}{c}\text { Gluteal Streaks/Drug } \\
\text { Delivery-Associated } \\
\text { RFF Application }\end{array}$ & $\begin{array}{c}\text { days of interval } \\
\text { between interventions }\end{array}$ \\
\hline
\end{tabular}

The volunteers were attended at a treatment outpatient clinic at Potiguar University. The sample was recruited in a non-probabilistic manner and randomly distributed into three groups through the site

"https://www.randomization.com", then color coded, thus ensuring blinding among them.

A semi-ablative fractional radiofrequency equipment, Artis model, manufactured by Tonederm, Anvisa 10411520022, a surgical procedure punch, iPhone 7 model camera manufactured by Apple, was used. Concept TI Strill Fluid Monodose manufactured by Mezzo Dermocosmetics [9], Anvisa registration number 25351.379480/2018-17, consisting of Aqua, Edta, Hydroxyacetophenone, 1,2Hexanediol, Caprylyl Glycol, Disodium Edta, Glycine Soybean Oil, Glycerin, Hydrogenated Lecithin, Citric Acid, Sh-Polypeptide-5, Butylene Glycol, Cetyl Hydroxyethylcellulose, Rutin, Palmitoyl Tripeptide-1, Palmitoyl Tetrapeptide-7, Phaseolus Iunatus Seed Extract, Bulbine Frutescens Leaf Juice, Bht, Bht (Phaseolus lunatus, rutin and matrikinas) and liftonin (hydroxypropyl methylcellulose, pullulan, porphyridium cruentum extract).

\section{Procedures}

The volunteers were informed about the procedures performed and signed the Consent Form. They received application in the abdominal or gluteal region according to the group in which they are inserted: Four sessions of semi-ablative fractional radiofrequency were applied. After the arrival of the volunteers, before the interventions, photographs were taken of the volunteers in an orthostatic position, at a distance of $60 \mathrm{~cm}$ between the camera and the photographed region with formation of 3 images: front, left profile and right profile. Neutral background was used to obtain standardized images.

Then, the intervention was initiated with the application of fractional radiofrequency equipment in the areas to be treated, using an 8-needle linear (tip) handle, which are disposable electrodes positioned on the equipment's accessories (handle). The right side was performed for fractional radiofrequency appli- 
cation and the left side was not applied, being the control side of the interventions. After completion of the interventions, the control side received the applications in the same way as the treated side.

The procedure was performed with the volunteers in supine position on a stretcher, without the use of topical or injectable anesthetics. The application was performed throughout the striae region making an overlapping stride, reaching the epidermal layer of the skin, with the applicator positioned vertically.

Four applications were performed in each volunteer. The parameters used in the Fractional Radiofrequency equipment were the same for both groups: energy pulse of $35 \mathrm{~mJ}$ per dot): $35 \mathrm{~mJ}$.

After the treatment, was done again the photographic record. The volunteers answered a questionnaire reporting the occurrence of possible adverse and/or deleterious effects occurring during and after treatment and about their satisfaction with the results through a satisfaction questionnaire, which is the aesthetic and global improvement scale (Global Aesthetic Improvement Scale (GAIS), by Narins [7] and adapted satisfaction questionnaire from Segot-Chicq et al. (2007) [8]. A questionnaire was applied to verify the inflammatory response (with the variables hyperemia, pain, edema, crust formation, presence of blemishes) and was applied after each intervention to analyze the evolution of these responses.

After the completion of the 4 sessions, 15 days after the last, a total of four volunteers were submitted to a surgical procedure called punch, which consists of collecting a small fragment for histological analysis.

The material removed was stored in a $10 \%$ neutral buffered formalin solution for $24 \mathrm{~h}$ at room temperature. Then the samples were processed by routine histotechnical procedures for hematoxylin and eosin (HE), Masson's trichrome (MT) and Picrosirius red staining.

For histomorphometric analyzes, photomicrographs of various microscopic fields were obtained at different magnification levels (40, 100 or 400). Digital images were obtained with binocular light microscope (Olympus CX31, Hamburg, Germany) with a camera attached and the images were analyzed with Image J software (NIH, Bethesda, MD, USA). Inflammatory cells (neutrophils, lymphocytes) quantified in 10 fields, considering the absolute number of cells per 400 magnification fields.

The total collagen area was evaluated by aniline blue staining on the MT slides, while the content was evaluated by PR staining (considering red-orange fibers after light polarization), both automated analyzes using ImageJ software. The collagen area or type I collagen index was calculated as follows: ([blue staining area in MT sections] or [red-orange staining area in PR sections]/[total field area]) 100\%).

Descriptive and inferential statistics of the data were performed using the program SPSS 22.0 (Statistical Package for Social Science version 22.0). Data normality was observed by the Kolmogorov-Smirnov (KS) test. For comparisons of measurements obtained in all evaluations (before, 15 and 30 days), the Bon- 
ferroni post hoc repeated measures ANOVA test was used. A significance level of $95 \%(\mathrm{p}<0.05)$ was adopted.

\section{Results}

The treatment was started with 40 volunteers, but due to part of the group, only 28 patients completed the interventions. Table 2 shows the anthropometric data of the study participants.

Table 2. Analysis of anthropometric characteristics between groups.

\begin{tabular}{cccc}
\hline & $\begin{array}{c}\text { Fractional Radiofrequency } \\
\text { semi-ablative }(\mathrm{n}=14)\end{array}$ & $\begin{array}{c}\text { Fractional Radiofrequency } \\
\text { semi-ablative associated } \\
\text { drug delivery }(\mathrm{n}=14)\end{array}$ & P value \\
\hline Age (years) & $28.5 \pm 2.5$ & $25.3 \pm 1.8$ & 0.87 \\
Weight $(\mathrm{kg})$ & $65.3 \pm 4.5$ & $60.1 \pm 3.8$ & 0.64 \\
BMI $\left(\mathrm{kg} / \mathrm{m}^{2}\right)$ & $21.6 \pm 1.3$ & $23.9 \pm 1.7$ & 0.75 \\
\hline
\end{tabular}

The test of anova one-way (95\% significance level and p value 0.05 ).

\subsection{Clinical Analysis}

Photographic recording of each group was performed in the first application and successively 15 and 30 days after the fourth application, depending on the group.

Figure 2 shows volunteer of the 15-day group, with treatment without association with drug delivery (before and after). Figure 3 shows volunteer of the 15-day group, with treatment associated with drug delivery (before and after). Figure 4 shows the volunteer of the 30-day group, with treatment without drug delivery (before and after). Figure 5 shows the volunteer of the 30-day group, with treatment associated with drug delivery (before and after).

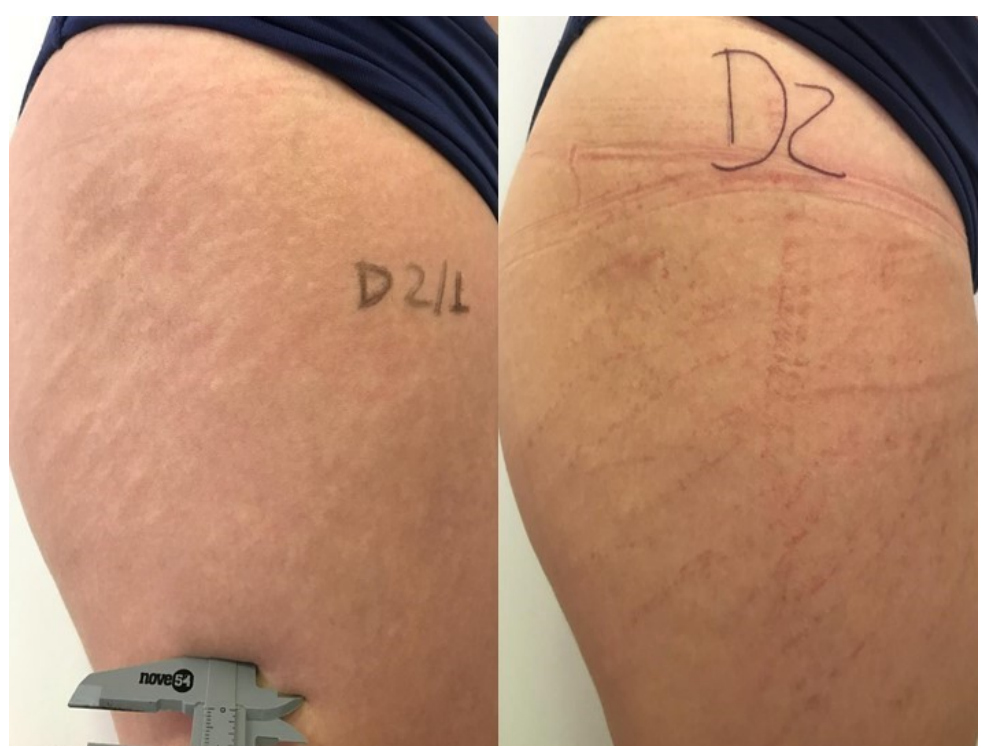

Figure 2. Volunteer of the 15-day group, with treatment without association with drug delivery (before and after). 


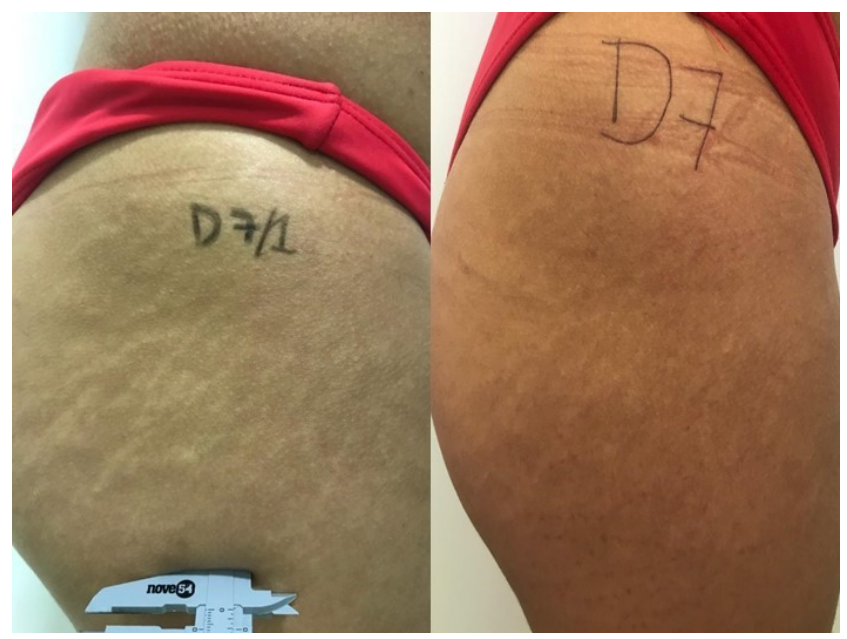

Figure 3. Volunteer of the 15-day group, with treatment associated with drug delivery (before and after).

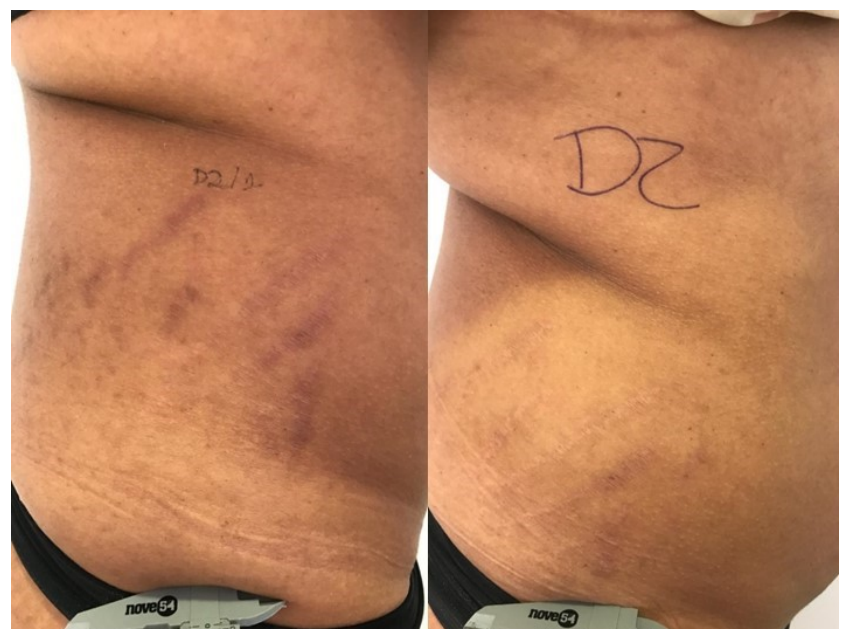

Figure 4. Volunteer of the 30-day group, with treatment without drug delivery (before and after).

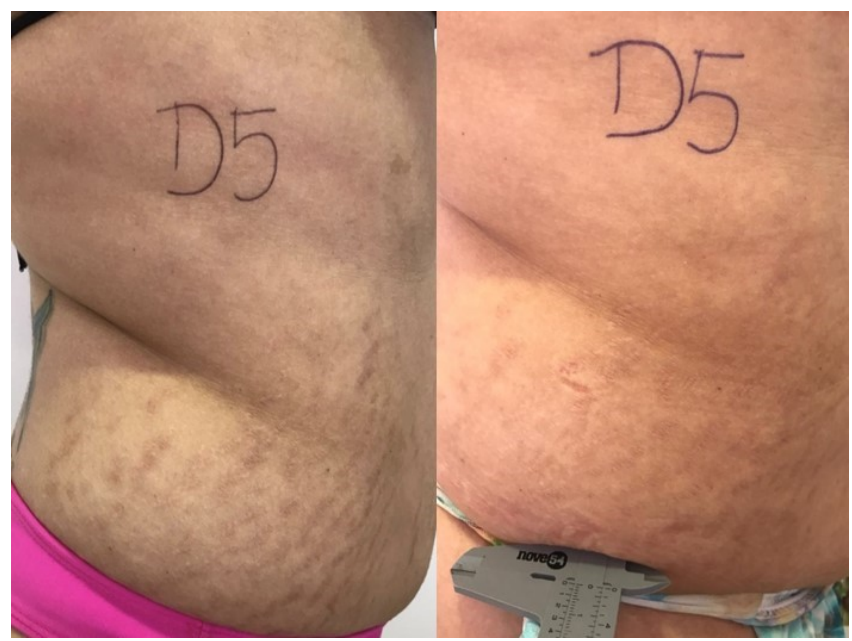

Figure 5. Volunteer of the 30-day group, with treatment associated with drug delivery (before and after). 


\subsection{Quantitative Analysis of the Histological Material of the Punch Fragment}

Histological analysis of the flaps removed from the volunteers in the abdominal regions was performed according to $\mathrm{HE}$ staining through a $100 \times$ increase in light microscopy.

Figure 6 presents the quantitative results of the histological analysis. In the inflammation variable, the G2A group (15 days without drug delivery) presented a higher inflammatory response $(p=0.001)$. In the analysis of the amount of fibroblasts, it was observed that the groups of 30 days of application with or without drug delivery presented a higher amount $(\mathrm{p}=0.002)$. It was also found that in these 30-day groups, there was a greater formation of type I collagen and blood vessels.
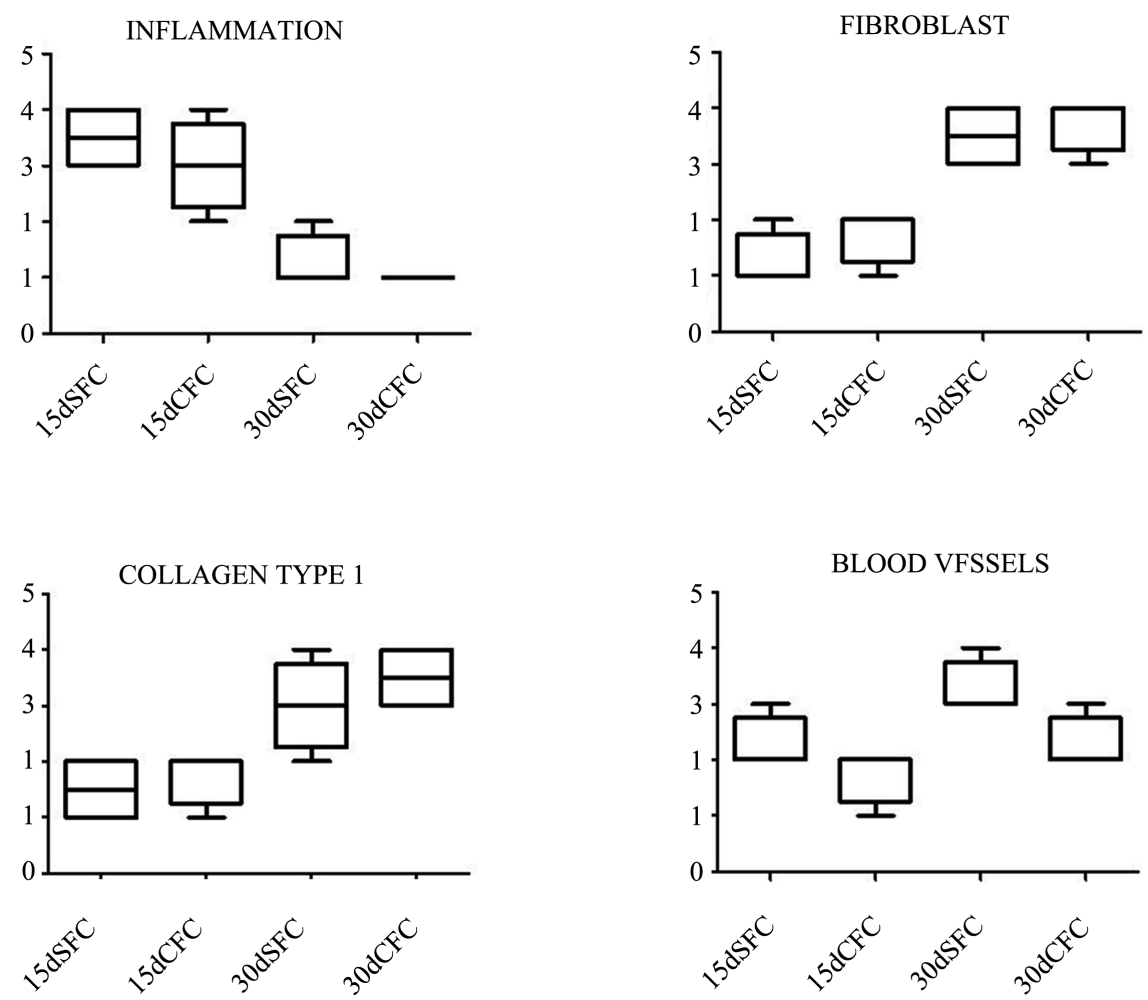

Figure 6. Analysis histology inflammation, fibroblast, collagen type1, blood vfssels.

\subsection{Analysis of Inflammation Questionnaires}

According to Figures 7-9, it can be observed, regarding the inflammation assessment questionnaires, that in relation to hyperemia, pain and edema, the groups G1A and G2A that did not use the RFF associated with the active principles presented upper inflammatory response, which remained until the fourth evaluation. Groups G1B and G2B, which used drug delivery, presented responses with lower inflammatory intensity. Regarding the formation of crusting and darkening of the stria, $100 \%$ of the volunteers in both groups observed the formation in the treated region only after the seventh day after the procedure. 


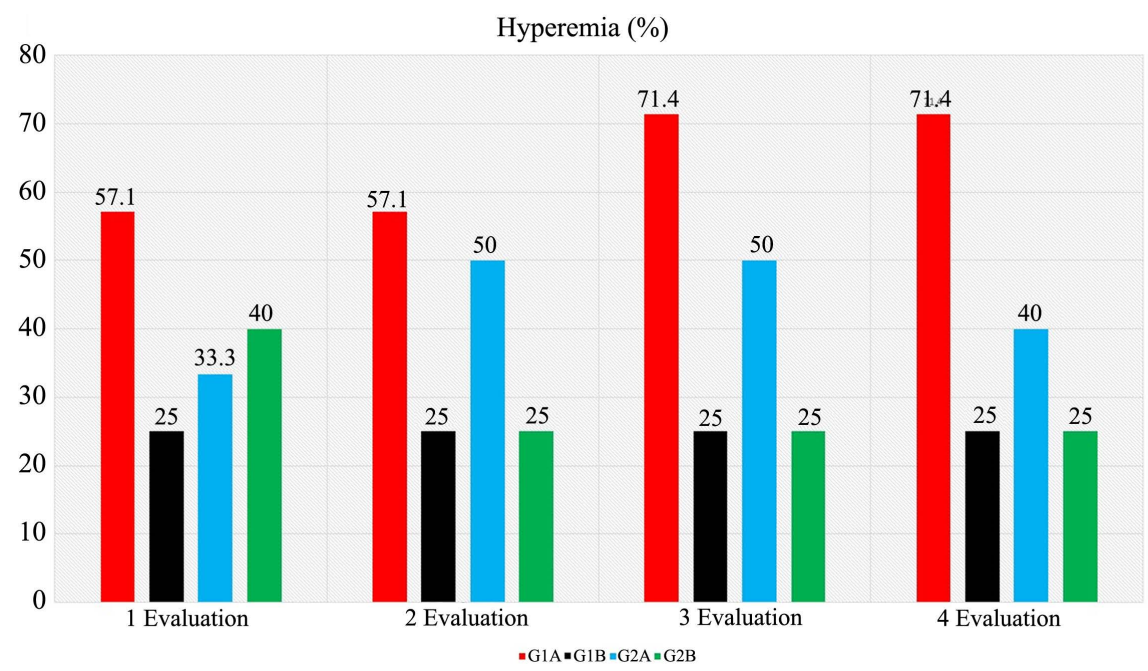

Figure 7. Hyperemia.

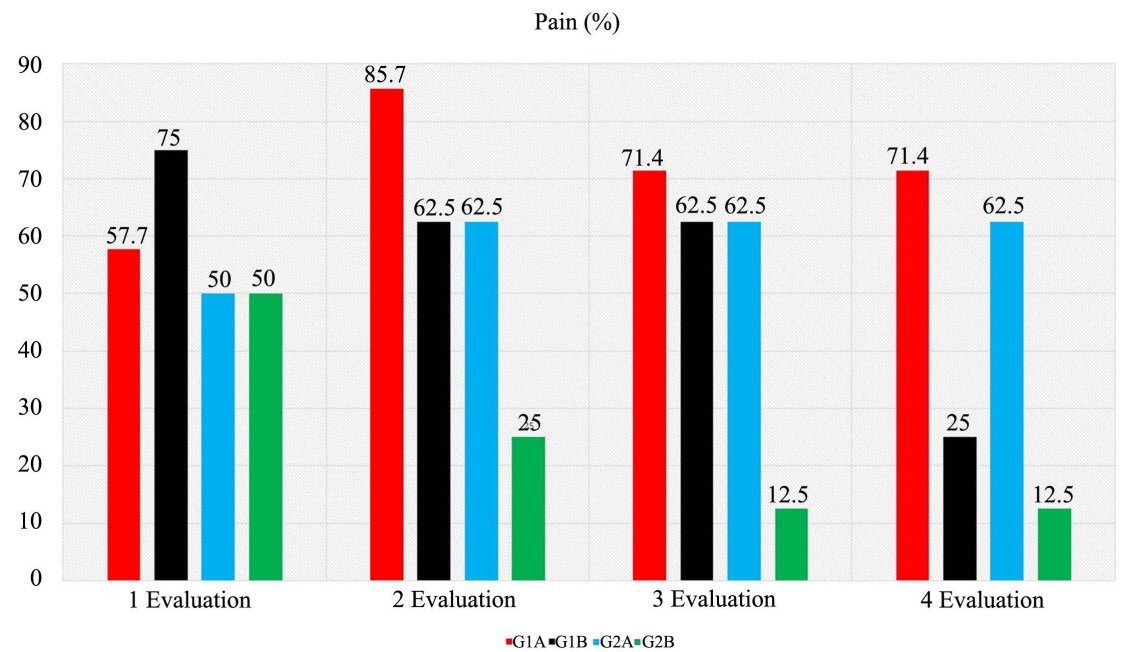

Figure 8. Pain.

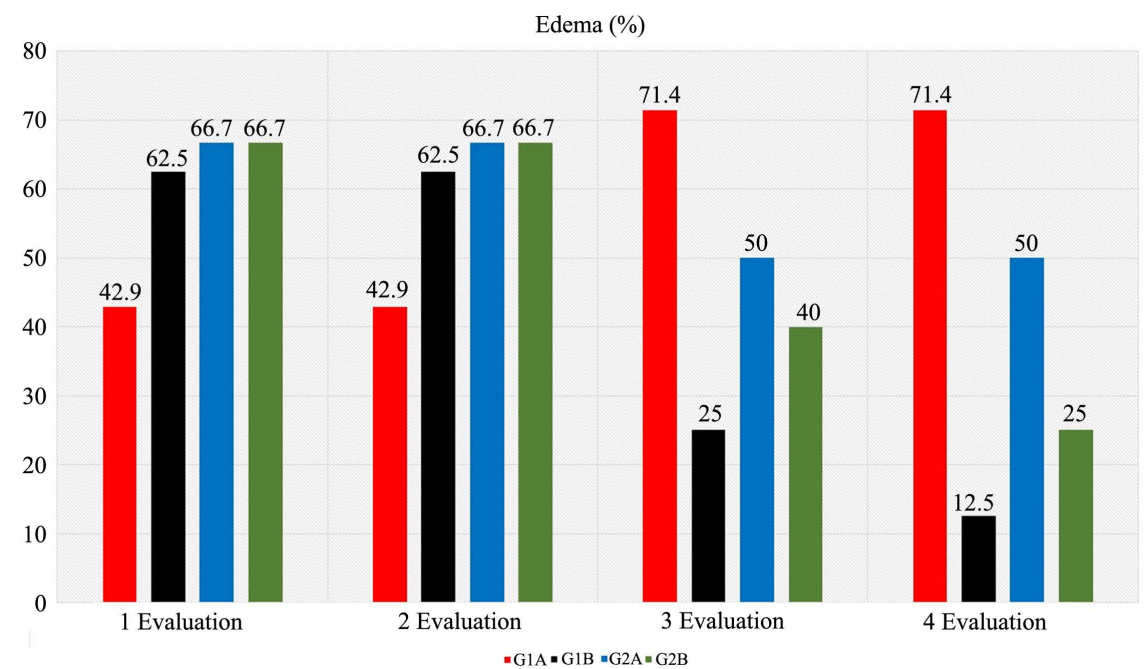

Figure 9. Analysis of adverse reactions and satisfaction. 


\subsection{Satisfaction Analysis}

At the end of the 4 sessions, the volunteers were asked to complete the satisfaction and skin reaction questionnaire, which consisted of 12 questions.

According to the answers to the questionnaire, it can be observed that in relation to hyperemia (redness) it was found that the group 15 days without cosmetic had an incidence of $57.1 \%$, however the group using dermocosmetic showed $75 \%$ of volunteers with hyperemia report. Regarding the analysis of 30 days without cosmetic $75 \%$ had hyperemia, while the group that used cosmetic about $50 \%$ had hyperemia. The observed hyperemia remained for approximately 2 to $3 \mathrm{~h}$ after the procedure.

The sensation of mild shocks was present only in the 15-day application groups, in $62.5 \%$ in the group without cosmetics $70 \%$ in the group that associated with the use of cosmetics. Marks on the skin were shown to be relatively temporary after application, and most had marks until the last session, disappearing after 20 days.

Regarding pain, it was observed that only the 15-day groups reported pain, presenting a similar report in the groups with or without cosmetics. According to the VAS scale, about $50 \%$ had level 5 pain and $25 \%$ level 6 pain in both groups. At pain level 8 about $50 \%$ of the group that performed the association with the cosmetic presented pain, while in the group without cosmetic this number remained at $12.5 \%$. Pain level 10 was reported in $12.5 \%$ of volunteers in both. Some adverse reactions such as skin blemishes or markings were not observed in the group that used the association with active ingredients.

In the analysis of satisfaction with the clinical results obtained, it can be observed that the group 15 days presented $12.5 \%$ satisfaction in the group 15 days without cosmetic, $25 \%$ in the group 15 days with cosmetic, while it was verified in the group 30 days, $25 \%$ of the non-cosmetic group had satisfaction, while $50 \%$ of the cosmetic group reported clinical improvement.

Regarding the description of the concept of the treatment performed, in the 14 days groups the level considered excellent was $25 \%$ in participants who did not use cosmetics and $28.6 \%$ in participants who used cosmetics. In the 30-day groups, we can observe similarity of excellent responses in $50 \%$ of the volunteers with or without the associated cosmetics. In the analysis of the global aesthetic improvement scale, in the group 15 days without cosmetics, it was reported that $14.3 \%$ reported it is much better and $57.1 \%$ reported it is better. In the 15 -day group analysis with cosmetic use, $12.5 \%$ reported better or much better and $50 \%$ reported unchanged responses. In groups 30 days, which did not use cosmetic, it was observed that $14.3 \%$ reported much better and $57.1 \%$ reported is better. The 30 days group that associated the use of cosmetics showed $25 \%$ much better and $50 \%$ better.

\section{Discussion}

The goal of this study was to analyse the effects of semi-ablative RFF associated 
or not with growth factors to improve the clinical and aesthetic aspect of stretch marks. Among the observed results, it was found that the use of semi-ablative RFF promoted an increase in local inflammation, which corroborates with the literature and is in alignment with the expected inflammation intensification responses, the increase in local circulation and the release of cell growth factors that would activate the fibroblast response, favouring tissue reorganization [10] [11].

The semi-ablative RFF is suggested to promote a modification in tissues with little or no cellular activity, such as the striated zone. The striae atrophic lesions could then be reorganized by the presence of physical agents that would favour activity in this tissue. However, when semi-ablative RFF was associated with growth factors present in topical cosmetics, different responses were observed. In general, an increase in fibroblast activation and an increase in collagen production, with a lower amount of inflammatory characteristics [12] [13] are expected responses in the treatment of alba striae with semi-ablative RFF, favouring the reorganization of the connective tissue [13] [14].

In this study it was observed that in the histological analysis, the use of growth factors favoured healing acceleration, faster reorganization of the connective tissue and less inflammatory signs, with responses varying according to the intervention group. The groups that underwent semi-ablative RFF application within 15 days had a more intense inflammatory response and the 30-day groups had a higher fibroblast activity. It is suggested that within 30 days, the healing process is advanced, thus, a larger amount of collagen was probably observed, as well as a minimization of the signs of edema, hyperaemia, and characteristic sore of the local inflammatory response [4] [14] [15].

The association of growth factors in the 15 days period showed a lower intensity of the inflammatory response when compared to the group that did not receive the application of growth factors. The application of semi-ablative fractional radiofrequency induces a controlled inflammatory response through needling and radiofrequency energy, expected in clinical practice and favouring tissue reorganization. However, the use of growth factors may modulate the inflammatory response associated with higher fibroblast activity and collagen production, with tissue reorganization, minimizing the inflammatory response [12].

During the inflammatory response, trypsin and chymotrypsin (formed by mast cell degranulation) or elastase (formed by macrophage) are responsible for the destruction of the connective tissue matrix protein, intensifying the lesion in the inflammatory region. The inflammatory induction generated by semi-ablative RFF stimulates the action of such enzymes. They also increase the presence of inflammatory signals, the association with active ingredients such as Phaseolus lunatus, rutin and matrikines, which promote an inhibitory effect on these trypsin and chymotrypsin, minimizing protein destruction and assisting in tissue reorganization [16] [17]. This mechanism would facilitate the promotion of greater control of the inflammatory response. It is also regarded as an antioxidant response, which stabilizes mast cell activity and participates in a reorganization of 
the damaged extracellular matrix in the process of stria formation [16] [17].

The groups with 30 days of intervention showed greater neocollagenization. The use of radiofrequency induces collagen production through a fibroblast activation mechanism. The collagen modulation generated by radiofrequency is already widely observed in the literature; however, the association of the semiablative FRP needling mechanisms favours an increase in this response that allows a greater neocollagenization intensity [4] [5] [6].

The 30-day group that made the association with cosmetics showed a similar response than the use of isolated semi-ablative RFF, however the response of the group with cosmetic association was with greater neocollagenization. The presence of the active ingredient TGF- $\beta 3$ is believed to stimulate collagenization, mainly by increasing the number of fibroblasts in the connective tissue. This result was verified in the histological analyses with increase in the amount of cells, as observed in the groups that made the association with growth factors. Although there was an increase in the number of cells in the group that performed the application of semi-ablative RFF alone, the association was more efficient. The TGF B3 is responsible for increased mesenchymal cell activity, and it is a factor that, when applied to the connective tissue, enhances the increase in fibroblast activity by increasing collagen production [18]. This neocollagenization allows a new dermal tissue structure and the remodelling of the region with striae, in addition to the formation of new vessels, increased blood flow, metabolic supply and synthesis of new proteins [19] [20] [21].

In the analysis of the responses to the questionnaires about inflammation, adverse reactions and satisfaction of the volunteers regarding the interventions, different answers were observed in each of the groups.

In the analysis of inflammation, regarding hyperaemia, pain and edema, the groups that did not use the RFF associated with the active principles showed a superior inflammatory response, which remained until the fourth evaluation. The groups that used drug delivery presented responses with lower inflammatory intensity. Regarding the formation of crustation on the stretch marks, $100 \%$ of the volunteers in both groups observed the formation in the treated region only after the seventh day from treatment. This result corroborates with the histological findings described above and with the inflammatory modulation suggested by the action of growth factors [6] [19] [22] [23].

In the analysis of adverse reactions, the group 15 days with the use of cosmetic showed higher hyperaemia (redness), with short lingering and greater shock sensation. According to the answers to the questionnaires, it can be observed that in relation to hyperaemia (redness) and pain level, that the 15 days group with cosmetic presented a faster response to inflammation. This answer may have been due to the questionnaires' subjectivity, but it coincides with the evaluated clinical findings [23] [24].

Satisfaction with treatment was observed in all groups, with reduction of striae alba; however, the groups with 30 days reported greater satisfaction with treatment, probably due to the conclusion of the therapeutic intervention cycle. In 
the analysis between the groups with or without the use of cosmetics, the group of 15 days with growth factors had a higher intensity of immediate inflammation response, but with a shorter effect duration. There is lower inflammation responses signalling in the groups using growth factors. In the 30-day analysis, no significant differences were observed in the response of the groups that used or not active ingredients.

\section{Conclusions}

The association of semi-ablative RFF with growth factors showed a reduction in inflammatory clinical signs, especially in the first 15 days, in addition to a higher collagen production, observed 30 days after application. Clinical results were satisfactory in all groups; however, in groups that were associated with growth factors, they reported better satisfaction with less intensity of inflammation.

Among the limitations of the study, the authors highlight the reduction in sample size due to volunteer withdrawal, besides the need for more objective means to analyze the treatment of striae alba, as well as the application of questionnaires and photographs.

\section{Acknowledgements}

We would like to thank Universidade Potiguar, UnP, Natal/RN for providing the structure and material for conducting the research.

\section{Conflicts of Interest}

The authors declare no conflicts of interest regarding the publication of this paper.

\section{References}

[1] Ud-Din, S., McGeorge, D. and Bayat, A. (2016) Topical Management of Striae Distensae (Stretch Marks): Prevention and Therapy of Striae Rubrae and Albae. Journal of the European Academy of Dermatology and Venereology, 30, 211-222. https://doi.org/10.1111/jdv.13223

[2] Liu, L., Ma, H. and Li, Y. (2014) Interventions for the Treatment of Stretch Marks: A Systematic Review. Cutis, 94, 66-72.

[3] Dai, R., Xie, H., Hua, W., Li, X.H. and Li, L. (2017) The Efficacy and Safety of the Fractional Radiofrequency Technique for the Treatment of Atrophic Acne Scar in Asians: A Meta-Analysis. Journal of Cosmetic and Laser Therapy, 19, 337-344. https://doi.org/10.1080/14764172.2017.1314507

[4] Carvalho, G.F., Silva, R.M.V., Mesquita-Filho Joaquim, J.T., Meyer, P.F., Ronzio, O.A., Medeiros, J., et al. (2011) Avaliação dos efeitos da radiofrequência no tecido conjuntivo. Revista Brasileira de Medicina, 68, 10-25.

[5] Meyer, P.F., de Oliveira, P., Silva, F.K.B.A., da Costa, A.C.S., Pereira, C.R.A., Casenave, S., et al. (2017) Radiofrequency Treatment Induces Fibroblast Growth Factor 2 Expression and Subsequently Promotes Neocollagenesis and Neoangiogenesis in the Skin Tissue. Lasers in Medical Science, 32, 1727-1736.

https://doi.org/10.1007/s10103-017-2238-2 
[6] Valentim da Silva, R.M., Andrade, N.C.C., Oliveira, T.R.S., Santos de Vasconcellos, L., Froes Meyer, P., Alexander Afonso, Y., et al. (2019) Effects of Semi-Ablative Fractional Radiofrequency in Dermal Tissue. International Journal of Advanced Research, 7, 1189-1202. https://doi.org/10.21474/IJAR01/8940

[7] Narins, R.S., Brandt, F., Leyden, J., Lorenc, Z.P., Rubin, M. and Smith, S. (2003) A Randomized, Double-Blind, Multicenter Comparison of the Efficacy and Tolerability of Restylane versus Zyplast for the Correction of Nasolabial Folds. Dermatologic Surgery, 29, 588-595. https://doi.org/10.1046/j.1524-4725.2003.29150.x

[8] Segot-Chicq, E., Compan-Zaouati, D., Wolkenstein, P., Consoli, S., Rodary, C., Delvigne, V., et al. (2007) Development and Validation of a Questionnaire to Evaluate How a Cosmetic Product for Oily Skin Is Able to Improve Well-Being in Women. Journal of the European Academy of Dermatology and Venereology, 21, 1181-1186. https://doi.org/10.1111/j.1468-3083.2007.02193.x

[9] TCimport (2017) MEZZO-Fluído monodose-STRILL, Rio de Janeiro, 1. http://mezzo.uni5.net/index.php?route=product/product\&product $\mathrm{id}=125$

[10] Al-Himdani, S., Ud-Din, S., Gilmore, S. and Bayat, A. (2014) Striae Distensae: A Comprehensive Review and Evidence-Based Evaluation of Prophylaxis and Treatment. British Journal of Dermatology, 170, 527-547.

https://doi.org/10.1111/bjd.12681

[11] Rawlings, A.V., Bielfeldt, S. and Lombard, K.J. (2012) A Review of the Effects of Moisturizers on the Appearance of Scars and Striae. International Journal of Cosmetic Science, 34, 519-524. https://doi.org/10.1111/j.1468-2494.2012.00751.x

[12] Hayashida, K., Fujioka, M., Morooka, S., Saijo, H. and Akita, S. (2016) Effectiveness of Basic Fibroblast Growth Factor for Pediatric Hand Burns. Journal of Tissue Viability, 25, 220-224. https://doi.org/10.1016/j.jtv.2016.06.007

[13] Pereira, R.T., Malone, C.M. and Flaherty, G.T. (2018) Aesthetic Journeys: A Review of Cosmetic Surgery Tourism. Journal of Travel Medicine, 25, tay051. https://doi.org/10.1093/jtm/tay051

[14] Raber-Durlacher, J.E., von Bültzingslöwen, I., Logan, R.M., Bowen, J., Rahman AlAzri, A., Everaus, H., et al. (2013) Systematic Review of Cytokines and Growth Factors for the Management of Oral Mucositis in Cancer Patients. Supportive Care in Cancer, 21, 343-355. https://doi.org/10.1007/s00520-012-1594-5

[15] Forbat, E. and Al-Niaimi, F. (2016) Fractional Radiofrequency Treatment in Acne Scars: Systematic Review of Current Evidence. Journal of Cosmetic and Laser Therapy, 18, 442-447. https://doi.org/10.1080/14764172.2016.1225964

[16] Puri, R. and Jain, S. (2012) Ethogel Topical Formulation for Increasing the Local Bio-Availability of 5-Fluorouracil: A Mechanistic Study. Anti-Cancer Drugs, 23, 923 934. https://doi.org/10.1097/CAD.0b013e3283534051

[17] Milewski, M., Brogden, N.K. and Stinchcomb, A.L. (2010) Current Aspects of Formulation Efforts and Pore Lifetime Related to Microneedle Treatment of Skin. EXpert Opinion on Drug Delivery, 7, 617-629. https://doi.org/10.1517/17425241003663228

[18] Derynck, R., Lindquist, P.B., Lee, A., Wen, D., Tamm, J., Graycar, J.L., et al. (1988) A New Type of Transforming Growth Factor-Beta, TGF-Beta 3. EMBO Journal, 7, 3737-3743. https://doi.org/10.1002/j.1460-2075.1988.tb03257.x

[19] Yang, T.L., Lee, P.L., Lee, D.Y., Wang, W.-L., Wei, S.-Y., Lee, C.-I., et al. (2018) Differential Regulations of Fibronectin and Laminin in Smad2 Activation in Vascular Endothelial Cells in Response to Disturbed Flow. J Biomed Sci, 25, Article No. 1. https://doi.org/10.1186/s12929-017-0402-4 
[20] Maddaluno, L., Urwyler, C. and Werner, S. (2017) Fibroblast Growth Factors: Key Players in Regeneration and Tissue Repair. Development, 144, 4047-4060. https://doi.org/10.1242/dev.152587

[21] Park, J.Y., Lee, E.G., Yoon, M.S. and Lee, H.J. (2016) The Efficacy and Safety of Combined Microneedle Fractional Radiofrequency and Sublative Fractional Radiofrequency for Acne Scars in Asian Skin. Journal of Cosmetic Dermatology, 15, 102 107. https://doi.org/10.1111/jocd.12195

[22] Song, Y.H., Zhu, Y.T., Ding, J., Zhou, F.Y., Xue, J.X., Jung, J.H., et al. (2016) Distribution of Fibroblast Growth Factors and Their Roles in Skin Fibroblast Cell Migration. Molecular Medicine Reports, 14, 3336-3342.

https://doi.org/10.3892/mmr.2016.5646

[23] Galimberti, D., Fenoglio, C., Ghezzi, L., Serpente, M., Arcaro, M., D’Anca, M., et al. (2019) Inflammatory Expression Profile in Peripheral Blood Mononuclear Cells from Patients with Nasu-Hakola Disease. Cytokine, 116, 115-119. https://doi.org/10.1016/j.cyto.2018.12.024

[24] Chandrashekar, B.S., Sriram, R., Mysore, R., Bhaskar, S. and Shetty, A. (2014) Evaluation of Microneedling Fractional Radiofrequency Device for Treatment of Acne Scars. Journal of Cutaneous and Aesthetic Surgery, 7, 93-97.

https://doi.org/10.4103/0974-2077.138328 